Article

\title{
Neonatal Pneumothorax- Five Years of Experience in a Tertiary Care Center
}

\author{
Miljana Z. Jovandaric ${ }^{1}$, Svetlana J. Milenkovic ${ }^{1}$ and Ivana R. Babovic ${ }^{2}$
}

[1] Clinic for Gynecology and Obstetrics, Department of Neonatology, University Clinical Center of Serbia, Belgrade, Serbia

[2] School of Medicine, University of Belgrade, Serbia

* Author and correspondence address: Miljana Z.Jovandaric MD PhD, Clinic for Gynecology and Obstetrics, University Clinical Center of Serbia, Department of Neonatology, Visegradska 26, 11000 Belgrade, Serbia. Tel +381 113663586 , E-mail: rrebecca080@gmail.com

Miljana Jovandaric (0000-0003-0294-6353) - ORCID

\begin{abstract}
Background and Objectives: Pneumothorax is a pathological condition characterized by the presence of air between the visceral and parietal pleura. To investigate incidence, clinical characteristics, risk factors, management and perinatal outcome among newborns with pneumothorax in a tertiary care center. Materials and Methods: A prospective observational study was conducted in Maternity hospital with tertiary NICU from 2015-2019. We included all neonates with pneumothorax born in our hospital and compared demographic characteristics, perinatal risk factors, anthropometric parameters, concurrent diseases, clinical course and method of chest drainage between full term ( $\geq 37 \mathrm{GW})$ and preterm (<37GW) newborns. Results: Mong 30.378 neonates, 74 developed pneumothorax $(2,4 / 1000$ newborns). The incidence of neonatal pneumothorax (NP) was higher in preterm group (59,5\%), with a mean age 34,62 GW in whole group. The mode of delivery was c. section in $68.9 \%$. NP occurred mostly on the right side $(47,3 \%)$, on the second day of life , in males $(67,6 \%)$. Chest drainage was performed in $64,9 \%$ of cases. Of 74 NP cases, $64(85.1 \%)$ recovered, $6(8,1 \%)$ died. Conclusion: Pneumothorax is a pathological condition of the newborn, which, if not diagnosed in time and treated adequately, leads to a fatal outcome.
\end{abstract}

Keywords: newborn; therapy; pneumothorax

\section{INTRODUCTION}

Pneumothorax implies the presence of air in the pleural space between the visceral and parietal pleura [1].

With the first inspiratory breath, the newborn creates a transpulmonary pressure greater than $100 \mathrm{~cm}$ of water column and opens the lungs that were closed in-utero. After a couple of breaths, this pressure normalizes and the lungs take over their function. If the transpulmonary pressure remains elevated for a long time, the alveoli rupture occurs, accumulating air between the visceral and parietal pleura. The air created in the interpleural space leads to a pathological condition called neonatal pneumothorax (NP). Pneumothorax developed in this way is called spontaneous (primary, idiopathic) [2]. The reason for the development of secondary pneumothorax in newborns may be respiratory distress syndrome (RDS), mechanical ventilation (MV), pneumonia, sepsis, aspiration of meconium, blood and amniotic fluid, or congenital lung malformations [3]. The consequences of primary and secondary pneumothorax are high pressure within the pleural 
space followed by lung collapse on the affected side, immediate hypoxia, hypercapnia and subsequent circulation collapse [4].

Based on the size of the pulmonary collapse, pneumothorax can be partial or total, unilateral or bilateral. A small amount of air can be asymptomatic and be resorbed by the body, while the presence of a larger amount of air endangers the life of the newborn $[5,6]$.

AIM: To investigate (evaluate) incidence, clinical characteristics, risk factors, management and perinatal outcome among newborns with pneumothorax in a tertiary care center.

\section{MATERIAL AND METHODS}

A prospective observational study was conducted at the Clinic for Gynecology and Obstetrics of the University Clinical Center of Serbia, Belgrade from January 2015 to December 2019. During this period, 30.378 newborns were born in our maternity hospital. In a tertiary NICU with 14 beds and 3911 admissions over a five-year period, we selected all infants with pneumothorax (NP) confirmed by X-ray and lung ultrasound.

Data were collected from medical records of newborns and their mothers. Informed consent for the treatment of pneumothorax was obtained from the mothers of all treated patients.

All methods were carried out in accordance with relevant guidelines and regulations. In our institution protocol for the treatment of Pneumothorax were approved / Ramadani method /, which was performed for the first time at the Institute for Neonatology in Belgrade, Serbia.

Patients were assessed on the basis of demographic characteristics (sex, gestational age, birth weight, APGAR score in the $5^{\text {th }}$ minute and need for resuscitation), perinatal (gestational disorders - gestational diabetes mellitus (GDM), hypertension, preeclampsia, HELLP syndrome, placental abruption, premature preterm rupture of the membrane (PPROM), mode of delivery, multiple pregnancies) and neonatal data (underlying pulmonary disorders - respiratory distress syndrome (RDS), pneumonia, meconium aspiration syndrome (MAS), transient tachypnea of the newborn (TTN) and comorbidities: intraventricular haemorrhage (IVH), retinopathy of prematurity (ROP), seizures, sepsis), as well as pneumothorax characteristics (laterality, age of occurrence, need for surfactant, oxygen therapy, nasal continuous positive airway pressure (nCPAP) and mechanical ventilation (MV) before NP, type of treatment (conservative or drainage), duration of drainage, MV and oxygen therapy post NP) and outcome.

We compared differences between term $(\geq 37 \mathrm{GW})$ and preterm $(<37 \mathrm{GW})$ newborns with NP and assessed risk factors for thoracal drainage.

In our hospital, chest drainage is performed according to Ramadani method. Special drainage iron-trocar $10 \mathrm{Ch}$, cut to half diameter $2 \mathrm{~cm}$ long to the top and sharpened at the top like a "needle" (Figure 1). After application of the trocar to a depth of $1 \mathrm{~cm}$, an $8 \mathrm{Ch}$ catheter is inserted into the groove with tweezers to a depth of $2 \mathrm{~cm}$, after which the trocar is removed and the catheter remains in the thoracic cavity and is connected to the permanent thoracic drainage system. 


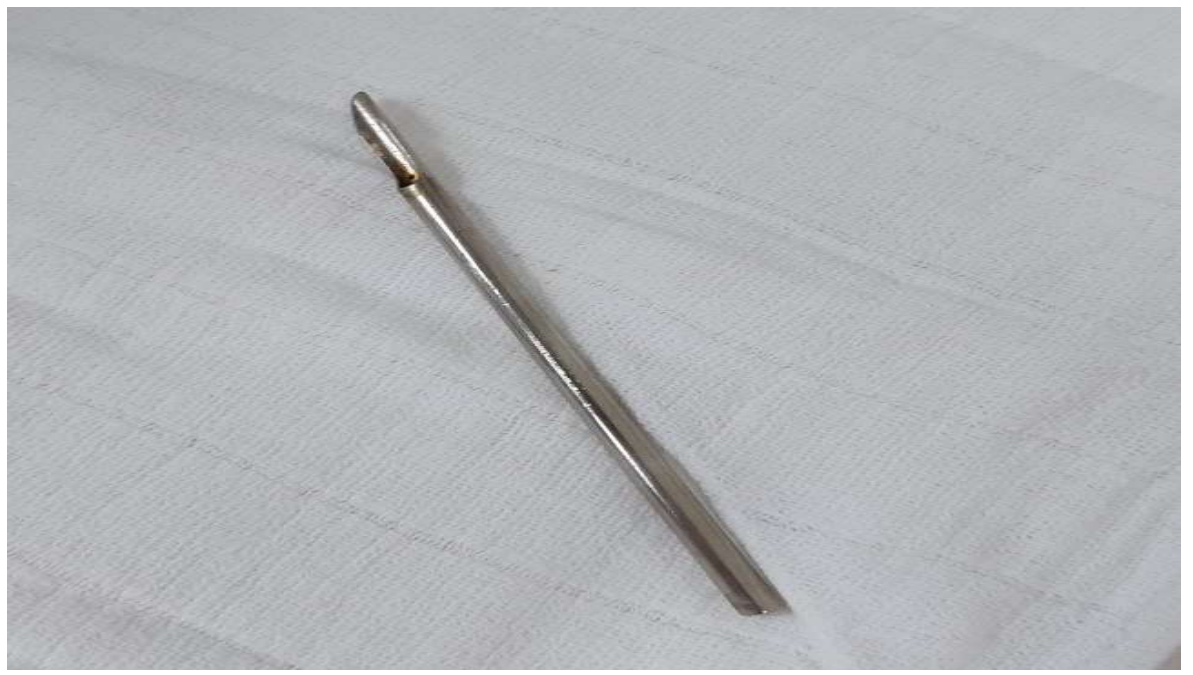

Figure 1. Special iron drain-trocar for thoracic drainage.

\section{RESULTS}

Among the 30,378 newborns born in our maternity ward, 74 developed pneumothorax (2.4 / 1000 newborns). 3911 newborns were admitted to the NICU and $1.89 \%$ of newborns were treated for NP. Six $(8.1 \%)$ newborns with NP died. Fifty $(67.6 \%)$ were boys and twenty-four (32.4\%) were girls. The average gestational age was $34.62+/-4.03$ $(\mathrm{GW})$, and the mean birth weight (BW) was $2570+/-970 \mathrm{~g}$. Nine (12.2\%) newborns were small for gestational age (SGA) and sixteen (21.6\%) large for gestational age (LGA). Sixty-four $(86.4 \%)$ were born in a singleton pregnancy. Fifty-one newborns $(68.9 \%)$ were born by caesarean section. APGAR score in the 5th minute and the need for resuscitation were found in $14(18.9 \%)$ patients. The most common gestational disorders in the group with NP were gestational hypertension, preeclampsia, HELLP in 13 (17.6\%) cases, GDM $(9.5 \%)$, placental abruption $(5.4 \%)$ and preterm premature of membrane (PPROM) in $6.8 \%$ of cases. Out of the twenty-two neonates with NP, $(29.7 \%)$ have RDS or other underlying lung disorders such as pneumonia $75.7 \%$, MAS $4.1 \%$, TTN $12.2 \%$ or persistent neonatal pulmonary hypertension (PPHN) 2.7\%. Among other neonatal disorders, sepsis was found in $17(23 \%)$ patients with NP, seizures in 14 (18.9\%), IVH gr III-IV in $4.1 \%$ and ROP in $5.4 \%$. Three newborns (4.1\%) have anomalies (Table 1 ).

Table 1. Demographic and perinatal data.

\begin{tabular}{cc}
\hline Variables & No $\mathbf{( \% )}$ \\
\hline Demographic data & \\
\hline Gender-male & $50(67,6)$ \\
\hline Gestational age $<37$ gw & $44(59,46)$ \\
\hline Gestational week- mean+/-SD & $34,62+/-4,03$ \\
\hline Birth weight -mean+/-SD & $2570+/-970,04$ \\
\hline SGA & $9(12,2)$ \\
\hline LGA & $16(21,6)$ \\
\hline Singleton & $64(86,4)$ \\
\hline Perinatal data & $7(9,5)$ \\
\hline Gestational diabetes & $13(17,6)$ \\
\hline Hypertensia, Preeclampsia, HELLP & $4(5,4)$ \\
\hline Placental abruption &
\end{tabular}




\begin{tabular}{cc}
\hline PROM & $5(6,8)$ \\
\hline C. section & $51(68,9)$ \\
\hline APGAR score $<5$ at $5^{\text {th }}$ min, resuscitation & $14(18,9 \%)$ \\
\hline Underlying lung disorders & $22(29,7)$ \\
\hline RDS & $56(75,7)$ \\
\hline Pneumonia & $3(4,1)$ \\
\hline Meconium aspiration syndrome & $2(2,7)$ \\
\hline PPHN & $9(12,2)$ \\
\hline Transent tachypnoea of the newborn & $3(4,1)$ \\
\hline Neonatal comorbidities & $4(5,4 \%)$ \\
\hline IVH & $14(18,9)$ \\
\hline ROP & $17(23)$ \\
\hline Seizuries & $3(4,1)$ \\
\hline Sepsis &
\end{tabular}

GW-gestational week; SGA-small for gestational week; LGA-long for gestational week; PROMpremature rupture of membrane; RDS-respiratory distress syndrome; PPHN-persistens pulmonary hypertension of neonate; IVH-intraventricular haemorrhage; ROP- retinopathy of prematurity.

NP most often occurred on the right side (47.3\%), on the second day of life (median 27h- range2-144h). Prior to NP onset, 25 newborns (35.1\%) were on mechanical ventilation (MV) and $31(41.9 \%)$ on nCPAP. $39.2 \%$ received surfactant before NP. The median $\mathrm{FiO} 2$ and $\mathrm{O} 2$ saturation prior to NP onset were $55+/-13.67 \%$ and $81.89+/-12.34 \%$, respectively. Chest drainage was performed in $48(64.9 \%)$ of cases, and conservative treatment in $26(35.1 \%)$ newborns. The drain was removed mainly after three days (82.4\%). The newborns received MV and oxygen therapy 5 a median (range 0-17), and a median 8 (range 2-30) days after the onset of NP. Out of 74 patients with NP, 64 $(85.1 \%)$ recovered, $6(8.1 \%)$ died, and $5(6.8 \%)$ were transported to other tertiary centers for surgery or other reasons. All transported newborns survived. Among the dead infants, one was born at term, 4 were extremely premature (less than $28 \mathrm{GV}$ ) 4 and one was born with anomalies (Congenital cystic adenomatoid malformation of lung) (Table 2).

Table 2. Clinical characteristics and management of neonatal pneumothorax (NP).

\begin{tabular}{cc}
\hline Laterality & No (\%) \\
\hline right & $35(47,3)$ \\
\hline left & $27(36,5)$ \\
\hline bilateral & $12(16,2)$ \\
\hline Time of PTX & $27(2-144)$ \\
\hline Hours median (range) & \\
\hline Treatment & $48(64,9)$ \\
\hline Thoracal drainage (TD) & $26(35,1)$ \\
\hline Conservative & $55+/-13,67$ \\
\hline Before PTX & $81,89+/-12,34$ \\
\hline FiO2 median +/-SD & $29(39,2)$ \\
\hline Sat O2 median+/-SD & $17(23)$ \\
\hline Surfactant before PTX &
\end{tabular}




\begin{tabular}{cc}
\hline nCPAP & $31(41,9)$ \\
\hline MV & $25(35,1)$ \\
\hline Treatment after PTX & $33(82,4)$ \\
\hline Drain <3 days & $5(0-17)$ \\
\hline days median (range) & $8(2-30)$ \\
\hline Oxygen therapy days median (range) & $63(85,1)$ \\
\hline Outcome & $6(8,1)$ \\
\hline Recovered & $5(6,8)$ \\
\hline death
\end{tabular}

Preterm infants with NP had RDS and AS $<5$ in the $5^{\text {th }}$ minute $(\mathrm{p}<0.05)$ significantly more often than neonates born at term (Table 3).

Table 3. Characteristic of preterm neonates with NP.

\begin{tabular}{cccc}
\hline variable & preterm & term & p \\
\hline male & $44(59,46)$ & $30(40,54)$ & NS \\
\hline Female & $26(59,1)$ & $24(80)$ & $\mathrm{NS}$ \\
\hline AS $<5$ & $18(40,9)$ & $6(24)$ & 0,005 \\
\hline Sepsis & $13(29,5)$ & $1(3,3)$ & $\mathrm{NS}$ \\
\hline RDS & $12(27,3)$ & $5(16,7)$ & 0,000 \\
\hline Pneumonia & $22(50)$ & 0 & $\mathrm{NS}$ \\
\hline TTN & $8(18,2)$ & $10(33,3)$ & 0,055 \\
\hline O2 before NP & $8(18,2)$ & $1(3,3)$ & $\mathrm{NS}$ \\
\hline nCPAP before NP & $7(15,9)$ & $10(33,3)$ & $\mathrm{NS}$ \\
\hline MV before NP & $21(47,7)$ & $10(33,3)$ & $\mathrm{NS}$ \\
\hline MV days median & $16(36,4)$ & $3(33,3)$ & $\mathrm{NS}$ \\
\hline O2 days median & $5(0-17)$ & $7(2-16)$ & $\mathrm{NS}$ \\
\hline Outcome & $9(2-30)$ & & $\mathrm{NS}$ \\
\hline recovered & & $26(86,7)$ & $\mathrm{NS}$ \\
\hline death & $37(84,1)$ & $1(3,3)$ & $3(10)$ \\
\hline transported & $5(11,4)$ & $2(4,5)$ &
\end{tabular}

When comparing NP groups with and without thoracic drainage, we found that the predisposing factor for thoracic drainage was preterm delivery, AS $<5$ in the fifth minute with resuscitation, sepsis, RDS, and prolonged MV stay (Table 4).

Table 4. Differences between groups with and without thoracic drainage.

\begin{tabular}{|c|c|c|c|}
\hline variable & Conservative No (\%) & $\begin{aligned} \underset{(\%)}{\text { Drainage }} & \text { No }\end{aligned}$ & p \\
\hline & $26(35,1)$ & $48(64,9)$ & \\
\hline $\begin{array}{l}\text { Gender } \\
\text { Male }\end{array}$ & $22(84,6)$ & $28(58,3)$ & NS \\
\hline Female & $4(15,4)$ & $20(41,7)$ & 0,021 \\
\hline Preterm & $11(42,3)$ & $33(68,8)$ & 0,027 \\
\hline $\mathrm{AS}<5$ & $1(3,8)$ & $13(27,1)$ & 0,015 \\
\hline C. section & $20(76,9)$ & $31(64,6)$ & NS \\
\hline GDM & $4(15,4)$ & $3(6,3)$ & NS \\
\hline HTA, PE, HELLP & $2(7,7)$ & $11(22,9)$ & NS \\
\hline
\end{tabular}




\begin{tabular}{cccc}
\hline Placental abruption & $3(11,5)$ & $1(2,1)$ & NS \\
\hline PROM & $1(3,8)$ & $4(8,3)$ & NS \\
\hline Sepsis & $2(7,7)$ & $15(31,3)$ & 0,021 \\
\hline RDS & $4(15,4)$ & $18(37,5)$ & 0,047 \\
\hline Pneumonia & $7(26,9)$ & $11(22,9)$ & NS \\
\hline TTN & $4(15,4)$ & $5(10.4)$ & NS \\
\hline $\begin{array}{c}\text { MV days median } \\
\text { (range) }\end{array}$ & $3(0-8)$ & $5(0-17)$ & 0,003 \\
\hline
\end{tabular}

\section{DISCUSSION}

The incidence of NP in the newborn age is 1 to $2 \%$, most often asymptomatic in $98 \%$ of cases. It is more common in premature babies, as much as $5-7 \%$ in newborns weighing less than 1500 grams [6]. In our study, the incidence of NP was 2.4/1000 (1.89\% in NICU), similar to the results from Tuzla 2/1000 [7], Oman 2.5/1000, [8], 1\% to 2\% in Turkey [9], Portugal 1.5\% in NICU [10], but less than in Saudi Arabia, 3.9\% in NICU [11], Egypt, 9.1\% [12], Iran, 5.8\% [13] and Canada, 2.5-6.7\% [14]. In a Danish study, the frequency of NP was 1.4/1000 [6], and in South India 1.3/1000 [15].

Premature birth and respiratory distress syndrome (RDS) are the most important causes of neonatal pneumothorax. The cause of RDS is insufficient production of surfactant in the lungs of a premature baby [14]. The basis of the manifestation of RDS can occur due to lung immaturity or disorders in the synthesis and function of the surfactant due to pathological processes (asphyxia, conatal pneumonia, gestational hypertension, GDM as well as preeclampsia of the pregnant woman) [16 - 18]. A higher probability of developing RDS in male newborns was investigated in animal models, in prematurely born male and female lambs [19]. Poor respiratory adaptation can result from gender differences in the composition of the phospholipid constituents of the surfactant and its function. Studies have shown a higher lecithin/sphingomyelin (L/S) ratio and higher concentrations of saturated phosphatidylcholine in amniotic fluid during human pregnancy with female fetuses, indicating a higher degree of lung maturity (in terms of surfactant composition) in females [20].

Male gender dominates as a risk factor for the development of pneumothorax in most studies, which was confirmed in our study, where two thirds of the sample with NP were male newborns [21 - 23].

Newborns born by caesarean section (CS) often have "wet lungs" followed by forced breathing which can lead to pneumothorax. Among neonates born by CS at term or moderately prematurely (30 - 36 weeks), the incidence of NP and respiratory problems is significantly increased. These problems can be avoided by postponing childbirth and administering antenatal steroid therapy where appropriate and possible [24].

Pneumothorax is more common in preterm infants $(34.62+/-4 \mathrm{GW})$, as shown by the results of other studies [10,11,24], although there are authors who found more children born at term with NP [6]. In our study, the percentage of LGA (21.6\%) among neonates with NP was slightly higher compared to the general population. As shown by other authors, NP is more common in infants born by caesarian section [10, 24].

The risk of developing pneumothorax is increased in neonates with respiratory distress syndrome (RDS), meconium aspiration syndrome (SAM), transient neonatal tachypnea (TTN), pulmonary hypoplasia, persistent pulmonary hypertension (PPHN), and in neonates with applied resuscitation after birth. Lung disease is the underlying condition in 59-61\% of infants with pneumothorax.The association of RDS, pneumonia, TTN and sepsis with NP is also significant in our neonates [10,11,24], although MAS is not represented in our results in a high percentage as in the mentioned studies. The low APGAR score in the 5th minute and resuscitation at birth is an important factor in the development of NP, as shown by other authors [7, 11, 24]. In our sample, the time of oc- 
currence of NP is at the beginning of the second day (median 27h), which is slightly later in relation to other authors [3,15], especially in children born at term [3].

In the diagnosis of pneumothorax, methods of translumination, lung ultrasound, chest X-ray are used. Lung ultrasound is used as a rapid method of diagnosing pneumothorax, when treatment can be initiated, as well as for monitoring of small pneumothorax. Although translumination and ultrasound of the lungs are increasingly used, chest radiography is a method of diagnosing and monitoring the treatment of pneumothorax [25].

Treatment of pneumothorax depends on the severity of the clinical picture, ie? the amount of air in the interpleural space. Smaller amounts of air (partial pneumothorax) are treated conservatively, by positioning (lying on the side of the pneumothorax), while larger pneumothorax requires urgent surgical chest drainage [26]. Treatment methods for larger pneumothorax include needle aspiration (NA) and chest drainage (CD). Needle aspiration, when needle is inserted between the ribs and removed after cessation of air aspiration, is recommended as the first line for the treatment of spontaneous pneumothorax [27]. In neonates on mechanical ventilation, some clinicians believe that needle aspiration will not provide adequate treatment and delay the placement of the thoracic drain [28].

Complications of thoracic drainage in neonates include thoracic injury, as well as scarring of the breast, especially in female neonates [29].

In our institution, larger pneumothoraxes in newborns were treated with a needle and rinsing catheter (Ramadani method), which was performed for the first time at the Institute for Neonatology in Belgrade, Serbia [30].

The largest number of newborns was on nCPAP (41.9\%) and on MV (35.1\%) before the onset of pneumothorax. Thoracic drainage was performed in $64.9 \%$ of infants with NP. We believe that the low mortality in our sample $(8.1 \%)$ compared to other studies where it reached $30-60 \%$ [10 - 13], is a consequence of the applied method according to Ramadani in thoracic drainage.

When we compared preterm infants and neonates with NP, we found that AS was less than 5 in the 5th minute, RDS and TTN (borderline) were significantly more common in the first group. Although $5 / 6$ of babies with NP who died were born prematurely $(11.4 \%$ vs. $3.3 \%)$, this difference was not significant.

Newborns who were treated by thoracic drainage due to pneumothorax were more often born prematurely than children without drainage, they had lower AS at birth, and RDS and sepsis were also a risk factor for NP onset also, children with thoracic drainage were longer on MV.

\section{CONCLUSION}

Neonatal pneumothorax is a condition associated with a life-threatening decline in lung function. In a high percentage of cases the failure to respond quickly results in death. Male sex, cesarean delivery and the application of nCPAP are associated with the development of NP. Our study also showed that prematurity, AS less than 5, RDS and sepsis are risk factors for the use of thoracic drainage in NP. A lower percentage of deaths in our study is attributed to the method of NP treatment according to Ramadani. Further research with a larger number of patients and multicentric studies should shed light on risk factors in order to develop new guidelines for NP management.

\section{Supplementary Materials:}

Figure 1. Special iron drain-trocar for thoracic drainage.

Table 1. Demographic and perinatal data. 
Table 2. Clinical characteristics and management of neonatal pneumothorax (NP).

Table 3. Characteristic of preterm neonates with NP.

Table 4. Differences between groups with and without thoracic drainage

Author Contributions: Conceptualization, M.Z.J. and S.J.M.; Data curation, M.Z.J., S.J.M. and I.R.B.; Formal analysis, M.Z.J.; Investigation, M.Z.J, S.J.M., I.R.B.; Methodology, M.Z.J . and S.J.M.; Resources, M.Z.J; Software, M.Z.J.; Supervision, MJZ, SJM. and I.RB.; Validation, M.Z.J.; Visualization, M.Z.J. and S.J.M.; Writing - original draft, M.Z.J., S.J.M. and I.R.B.; Writing - review and editing, M.Z.J. All authors have read and agreed to the published version of the manuscript, and they have equal contribution to the first author.

Funding: This research received no external funding.

Institutional Review Board Statement: The study was conducted according to the guidelines of the Declaration of Helsinki. Ethical review and approval were waived for this study due to a study of an observational character.

Informed Consent Statement: Informed consent was obtained from all subjects involved in the study.

Data Availability Statement: All data are available in the archives (database) Department Neonatology, Clinic for Gynecology and Obstetrics, University Clinical Center of Serbia, Belgrade, Serbia. Acknowledgments: To all my friends and Department of Neonatology, Clinic for Gynecology and Obstetrics, University Clinical Center of Serbia, Belgrade.

Conflicts of Interest: The authors report no conflict of interest. The authors are solely responsible for the content and writing of the article.

\section{References}

1. Noppen M, De Keukeleire T. Pneumothorax. Respiration 2008;76:121-127

2. Smith J, Schumacher RE, Donn SM, Sarkar S. Clinical course of symptomatic spontaneous pneumothorax in term and late preterm newborns: report from a large cohort. Am J Perinatol. 2011;28:163-168

3. Aly H, Massaro A, Acun C, Ozen M. Pneumothorax in the newborn: clinical presentation, risk factors and outcomes. J Matern Fetal Neonatal Med. 2014 ;27:402-406.

4. Arshad H, Young M, Adurty R, Singh AC. Acute pneumothorax. Crit Care Nurs Q. 2016;39:176-189.

5. Park SW, Yun BH, Kim KA, SyKo, Lee YK, Shin SM. A Clinical Study abaut Symptomatic Spontaneous pneumothorax. Korean J Perinatol. 2006;17:304-309.

6. Vibede L, Vibede E, Bendtsen M. Pedersen L. Ebbesen F. Neonatal Pneumothorax: A Descriptive Regional Danish Study. Neonatology 2017;111:303-308

7. Hadzic D, Skokic F, Husaric E, Alihodzic H, Softic Dz, Kovacevic Dz. Risk Factors and Outcome of Neonatal Pneumothorax in Tuzla Canton. Mater Sociomed. $2019 ; 31: 66-70$.

8. Rehan A, Shakeel A, Maqbool Q, Maheshwari P, and Rehan K. Pneumothoraces in a Neonatal Tertiary Care Unit: Case Series. Oman Med J. 2013 ; 28: 67-69.

9. Esme H, Doğru O, Eren S, Korkmaz M, Solak O. The factors affecting persistent pneumothorax and mortality in neonatal pneumothorax. Turk J Pediatr 2008. ;50:242-246

10. Silva IS, Flôr-de-Lima F, Rocha G, Alves I, Guimarães H. Pneumothorax in neonates: a level III neonatal intensive care unit experience. J Pediatr Neonat Individual Med 2016;5:e050220.

11. Al Matary A, Munshi HH, Abozaid S, Qaraqei M, Wani TA, Abu-Shaheen AK. Characteristics of neonatal pneumothorax in Saudi Arabia: three years' experience. Oman Med J. 2017;32:135 -139.

12. Abdellatif MA, Abdellatif DA. Pneumothorax in the neonatal intensive care unit in Cairo University Hospital. J Egypt soc parasitpl. 2012;42:495-506

13. Navaei F, Aliabadi B, Moghtaderi M, Kelishadi R. Predisposing factors, incidence and mortality of pneumothorax in a neonatal intensive care unit in Isfahan, Iran. Zhongguo Dang Dai Er Ke Za Zhi. 2010 ;12:417-20.

14. Duong HH, Mirea L, Shah PS, Yang J, Lee SK, Sankaran K. Pneumothorax in neonates: Trends, predictors and outcomes. J Neonatal Perinatal Med. 2014;7:29-38.

15. Joshi A, Kumar M, Rebekah G, Santhanam S. Etiology, clinical profile and outcome of neonatal pneumothorax in tertiary care center in South India: 13 years experience. J Matern Fetal Neonatal Med. 2020 Feb 19;1-5.

16. Haddad GG, Fontan JJP. Development of the respiratory system. In: Behrman RE, Kliebman RM, Jenson HB, editors. Nelson Textbook of Pediatrics. Philadelphia: WB Saunders; 2004. pp. 1357-9.

17. Rubarth BL, Quinn J. Respiratory Development and Respiratory Distress Syndrome. Neonatal Netw. 2015;34:231-8. 
18. Dotson K, Johnson LH. Pediatric spontaneous pneumothorax. Pediatr Emerg Care 2012;28(7):715-20; quiz 721-3.

19. De Matteo R, Ishak N, Hanita T, Harding R, Sozo F. Respiratory adaptation and surfactant composition of unanesthetized male and female lambs differ for up to $8 \mathrm{~h}$ after preterm birth. Pediatr Res 2016;79:13-21.

20. Ishak N, Hanita T, Sozo F, Maritz G, Harding R, De Matteo R. Sex differences in cardiorespiratory transition and surfactant composition following preterm birth in sheep. Am J Physiol Regul Integr Comp Physiol 2012; 303: R778- R 789.

21. Apiliogullari B, Sunam GS, Ceran S, Koc H. Evaluation of neonatal pneumothorax. J Int Med Res 2011;39:2436-2440.

22. Girard I, Sommer C, Dahan S, Mitanchez D, Morville P. [Risk factors for developing pneumothorax in full-term neonates with respiratory distress]. Arch Pediatr. $2012 ; 19: 368-73$.

23. Malek A, Afzali N, Meshkat M, Yazdi NH. Pneumothorax after mechanical ventilation in newborns. Iran J Pediatr. 2011;21:45-50.

24. Ya-Lan Tan, Yang Zhan, Jia Geng, Wei Chen, Wan-Liang Guo. Predictors of chest drainage of pneumothorax in neonates. Braz J Med Biol Res. 2020; 53(8): e9469.

25. Cattarossi L, Copetti R, Brusa G, Pintaldi S. Lung Ultrasound Diagnostic Accuracy in Neonatal Pneumothorax. Can Respir J. 2016; 2016: 6515069

26. Volpicelli G. Sonographic diagnosis of pneumothorax.Intensive Care Med. 2011 ;37:224-232.

27. Bruschettini M, Romantsik O, Ramenghi LA, Zappettini S, O'Donnell CP, Calevo MG. Needle aspiration versus intercostal tube drainage for pneumothorax in the newborn. Cochrane Database Syst Rev. 2016;(1):CD011724.

28. Murphy MC, Heiring C, Doglioni N, Trevisanuto D, Blennow M, Bohlin K, Lista G, Stucchi I, O'Donnell CPF. Effect of Needle Aspiration of Pneumothorax on Subsequent Chest Drain Insertion in Newborns: a Randomized Clinical Trial. JAMA pediatrics, 2018, 172, 664-669.

29. Filosso PL, Guerrera F, Sandri A, Roffinella M, Solidoro P, Ruffini E, Oliaro A. Errors and Complications in Chest Tube Placement.Thorac Surg Clin. 2017 ; 27:57-67.

30. Ramadani R. Dijagnosticke i terapijske intervencije u Neonatologiji. Grafoprint, Beograd, 2001; 81-89. 